\title{
DESCR IPTIONAL ANAPHORA IN DISCOURSE REPRESENTATION THEORY
}

\author{
Michael Hesa \\ Department of Computer Sclences, University of Zurich \\ Winterthurerstr. 190 \\ CH-8057 Zurich. Switzerland
}

\section{ABSTRACT}

Standard Discourse Representation Theory (DRT) was designed mainiy to explain the so-called donkey-sentences. The pronouns playing such a prominent role in ell these sentences belons. however, exclusively to one (particularly simple) type of pronoun. We try to extend DRT in order to cover an equaliy lmportant type of pronoun, the so-called "descriptional" pronoun. D1scourse referents are now used to carry information on the intension of their referents as well as on the extension. Th1s allows, at the same time, to sugsest accessiblitty rules for pronouns which are more approprlate than those sugzested by traditional DRT. These new rules are based on the senericness of the sentences Involved.

1. PRONOMINAL REFERENCE AS STARTING POINT FOR DISCOURSE REPRESENTATION THEORY

One of the starting points for the development of DRT in Kamp's original paper (Kamp 1981) was the seemingly erratic behaviour shown by indefinite noun phrases under a traditional logical analysis. and the equaliy erratic interactions that seem to obtain between inderinite noun phrases and inter-sentential and intra-sentential pronominal reperences to them. OP particular interest was the behaviour of Indefinite noun phrases in the so-called donkey-gentences.

\subsection{Definiteness and Indefiniteness in Traditional Linguistic Theory}

The traditional, and intuitively quite convincing. view has it that depinite noun phrases refer to an object that is already pamiliar to the apeaker (and possibly also to the listener). Whereas indefinlte noun phrases introduce new objects. This theory looks convincing as long as we consider explicit definites, as in

1) John owns a donkey. John beats the donkey where the donkey is introduced as existing by the indefinite noun phrase and referred to as familiar by the following definite noun phrase, Personal pronouns are, under the accepted interpretation, contracted forms of definite noun phrases, and the familiarlty hypothesis often works reasonably well for them. too: In the following paraphrase of 1:

\section{2) John owns a donkey. He beats it}

the definite pronoun refers to the donkey which 18 familiar after it has been introduced by an indefinite noun phrase. and the definite pronoun 18, in other words, co-referential with the preceding indefin1te noun phrase. For this reason the traditional interpretation of noun phrases and pronouns 1s called "reperential".

But problems surface $1 f$ we consider sentences such as

3) John doesn't own a donkey

4) Every boy likes his mother

Ne1ther does the indefinite noun phrase in 3 assert that there 19 a donkey that John owns. nor can we really say that the pronoun "h1s" in 4 repers to something fam1liar. Indeed, we can hardly say that it repers to anything at all: If we stick to the traditional view of what reperence 18 . v1z. a relationship between an expression of lanfuage and a real object. then there can be no reference at ald in 4 , since no existence of any boys was ever asserted. It was examples such as those that brought the whole ramiliarity theory into disrepute (cf. the short historleal outline given by Heim 1983).

\subsection{Definiteness and Indefiniteness in Logically Oriented Linguistics}

One radical solution to the problem of non-referring noun phrases was suggested by Russell in his classical theory of Descriptions. In 1 t. both definite and indefinite articles are interpreted as existential quantifiers (with the addi- 
tional constraint of uniqueness in the case of the definite article). Noun phrases do not refer at all, they all assert existence (with the exception of "loglcally proper names", whose exlstence Russell could never prove). Example 3 would become "It is not the case that there $1 \mathrm{~s}$ a donkey and John owns $1 \mathrm{t}$ ", and 4 would become "Por every boy there 18 exactly one mother such that he loves her". Now the truth values for these sentences come out right. This interpretation 18, accordingly, called the "quantificational theory of noun phrases". Under this analysis pronouns correspond to the var1ables bound by quantifiers in First order Predicate Calculus.

Until recentiy most lingulsts and logiclans saw no other solution to the problems exemplifled by sentences 3 and 4 than to adopt Russell's theory. But the quantiflcational theory of noun phrases does not seem to help in multi-sentence discourses such as 1 and 2 . Here the trad1tional referential theory st11l seemed to have much more explanatory power. But this meant, unfortunately. that noun phrases, inclusive pronouns, must be interpreted in (at least) two fundamentally different ways: In single sentences such as 3 and 4 as quantifiers and bound variables. respectively. Without any referring function, and in multi-sentence discourses such as 1 and 2 as referring expressions.

But par worse. there are certaln cases where neither of these interpretations seems possible. The best-known examples are the so-called donkey-sentences:

5) If John owns a donkey he is happy

6) If John owns a donkey he beats it

The most natural translation of 518

7) EXISTS $x$ : (donkey $(x)$ AND owns (john, $x$ )) $\rightarrow$ happy (john)

where the indefinite article can be represented as an existential quantifier. and this is in keeping with our intultion: A valid paraphrase of this sentence 18 "If there 18 some donkey that John owns he 1 s happy". Example 6 , on the other hand, must set, as the only intultively convincing representation.

8) ALL $X$ : ((donkey $(X)$ AND owns $(j o h n, x)$ ) $\rightarrow$ beats $(j$ ohn, $x)$ )

where the indefinite article has to be translated as a universal quantifier ("For any donkey that John owns it will be the case that he beats 1t"). The only syntact1c difference between the two sentences is the pronominal reference to the noun phrase "a donkey", made in 6 but missing in 5. The manner in which an arbitrarily (in principle) far removed pronoun in the surface sentence can turn an exletentlal quantifier into aniversal one has been puzzling logiclans and linguists for a long time. The referential theory of noun phrases does not help, elther, In these cases. We really are at a loss to explain donkey sentences.

But there are yet more functions of noun phrases, and in particular of pronouns. whlch seem to resist any stralghtforward logical or "traditional" interpretation: The Bach-Peters sentences, where pronouns point crosawise forward and backward ("The pliot who shot at lt hit the Mir that chased him"), and the so-called E-type pronouns, which point from outside into quantified statements ("Few M.P.s came to the party but they had a good time" (Evans 1980:338). One particular k1nd of the Etype pronouns will be given a lot of attention below.

\subsection{Pronominal Reference in Discourse Representation Theory}

Kamp's DRT and Helm's File Change Semantics are two (very similar) attempts to unify the familiarity/novelty theory and the quantificational theory of noun phrases and, as special cases. the referential theory and the bound-variable theory of pronouns. Both authors took up an 1dea of Kartunen's (e.g. Kartinen 1976). v1z. that we have to distinguish between "normal" referents. 1.e. real objects in the world (or a model of $1 t$ ). and special discourse referents, whose existence in the discourse does not in itself say anything about the existence of any objects in the world (or the model). Indefinite noun phrases and proper names introduce (1.e. assert the existence of) new discourse referents. These discourse referents constitute the universe of discourse. The remsining information contained in the sentence defines the cond1tions on the discourse referents. Now the conflict between the two interpretations op noun phrases can be resolved: We can "refer" (by means of defintte noun phrases or definite pronouns) to discourse referents (this is the referencefamiliarity component) but these entities are not real world objects but something functionaliy similar to the variables used in quantified statements (this is the quantification component). This solution works for anaphorlc links from inside a sentence (such as 6 ) as well as for those from outside (e.g. 2), 1.e. we have a way to treat both lsolated sentences and discourses.

Notationally, discourse referents and conditions are arrenged in Discourse Representation Structures (DRSs). Following Guenthner 1986, we list on the left 
hand side of a DRS the members of the universe of discourse, on the right hand side the conditions on them. Proper names are not used as individual constants; different individuals can have the same name. and proper names are therefore translated as normal predicates. Contrary to Kamp's original notation, but in agreement with the practice now generally adopted. we do not record the whole analysis process of each sentence in the DRS. The first sentence of example 2 would create an initial DRS

9) [u1, u2: John(u1), donkey(u2). owns $(u 1, u 2)]$

whereas the second sentence would extend th1s DRS to become

10) [u1, u2: John(u1), donkey(u2). owns (u1, u2), beats (u1,u2)]

Sentences 5 and 6 , on the other hand. would become

11) [u1: John(u1), [u2: donkey(u2). owns (u1.u2)] $\rightarrow->$ happy (u1)]

12) [u1: [u2: John(u1), donkey(u2). owns $(u 1, u 2)]-->$ [beats $(u 1, u 2)]]$

Finally, a sentence such as "If a man loves a woman he will glve her a ring" would be reoresented as

13) [ [u1,u2: $\operatorname{man}(u 1)$, woman(u2). loves(u1.u2)] $\rightarrow$ (u3: ring(u3), gives (u1, u3, u2)] ]

\section{RESTRICTIONS ON PRONOMINAL REFERENCE IN DISCOURSE REPRESENTATION THEORY}

\subsection{The Classical Examples}

It is claimed in the literature on DRT that the construction principles of DRS also explain certain restrictions on pronominal reference. Prime examples are discourses with quantifled sentences such as

14) Every man who owns a donkey beats it. * It has a white patch on its forehead

where the pronoun "1t" in the second sentence cannot be linked anaphorically to the noun phrase in the pirst sentence. although the "1t" In the pirst sentence (a donkey-sentence) can. The same thing holds for conditional sentences and negations.

DRT in its present form models the accessibllity restrictions encountered in these examples by embedding DRSs inside each other, and by postulating appropriate accessibility rules for snaphoric links (see Plnkal (1986) for a sood overview. and extensions concerning depinite noun phrsies). While the discourse referents of proper names are "pushed up" to the princ1pal DRS, even when embedded, the others are left "buried" Inside the embedded DRSs. Accessibility rules make sure that anaphorlc links cannot reach down into embedded DRSB, and only "backwards" in embedded DRSs. We want to show in this paper that the examples normally used to show accessiblifty restrictions. e.s. 14. are unacceptable not for the reasons given in DRT, but for entirely different reasons. We w1ll furthermore show that other phenomena of anaphora cannot be explained by DRT in 1 ts present form. We will then suggest appropriate modipications to DRT to compensate for these deflciencles.

\subsection{Counterexamples}

It $1 \mathrm{~s}$ certainiy true that discourse erasments such as 14 are unacceptable, but not because pronouns cannot anaphorically point into quentified (conditional. negated) atatements. The following counterexamples show thet they can. under certain circumstances:

15) Every man who truly loves a woman respects her. He treats her as his equal and expects the same thing of her

16) Whenever a hunter spots a deer he will kill it. He will cut it up and carry it home

The pronouns "her" and "1t" In the second aentence of each example refer to discourse referents which should be inaccessible, according to DRT. The accessiblity rules for embedded DRSs, as used in traditional DRT, are too restrictive.

3. THE FUNCTION OF DISCOURSE REFERENTS IN TRADITIONAL DISCOURSE REPRESENTATION THEORY

If we want to cover cases such as 15 and 16 we not only have to modify the accessibllity restriction rules but also modify our 1dea of what discourse referents stand for. We sald that DRT tries to unify the reperential and the quantificational interpretation of noun phrases. If we use Horn Clause Loric (HCL) as the target language for the interpretation of sentences we set a particularly simple correspondence. In an example such as 2 ("John owns a donkey. He beats $1 t$ ") the "1t" In the second sentence ultimately refers to the same individual as the noun phrase "a donkey". and the discourse referent introduced by "a donkey" stands for the Individual constant representing this individual in HCL (in standard First order Predicate Calculus we would, of course, have to use a varlable). In sentences such 14 "Every man who owns a donkey beats 1t", however, the pronoun plays the role of an individual variable in HCL 
(and in standard First Order Predicate Calculus). Discourse referents now turn out to be an abstraction of the concept of Individuel veriable and individual constant in HCL. In other words, a discourse referent stands for an individual variable if the sentence in which it occurs is ceneric, and for a constant if it is nonsenerlc'. as the transiation of examples 2 (first sentence) and 15 shows:

[u1,u2: john(u1), donkey(u1), own $(u 1, u 2)]$

becomes

own (john, donkey 1 ).

inst (donkey 1 , donkeys).

and

[u1, u2: $\operatorname{man}(u 1)$, woman (u2), loves $(u 1, u 2)-\rightarrow$ respects $(u 1, u 2)]$

becomes

respects $(M, W):-\operatorname{man}(M), \operatorname{woman}(W)$, loves $(M, W)$.

In addition, discourse referents have to "dras along" all the conditional expresslons in which they occur in the DRS ("loves(M,W)" etc.) from there to the logical representation. Th1s concept of what discourge referents stand for has to be modifled if we want to cover cases such as 15 and 16 .

\section{Types of Anaphoric Reference to Noun Phrases}

\subsection{Denotational Anaphora}

In both of the two types of pronominal anaphora considered so far, reference and bound variable anaphora, there is $a$ direct mapplng from pronouns to discourse referents, and another one from discourse referent to individual constant or variable in the logical representation. A constant stands for a real object in the world, and a variable will stand for one at evaluation time: this object $1 \mathrm{~s}$ the denotation op the pronoun. For this reason both types of anaphore considered so far are usually called "denotational anaphora". This name 18 unfortunate as $1 t$ blurs the main 1dea behind this type of anaphora, viz. the pact that "denotational anaphora" is an abstraction of referential (or: denotational) and non-referential (or: bound varlable) uses of pronouns and other noun phrases. It would be much better to speak of extensional anaphora Instead.

1. We treat truly generic sentences. such as 15 , and general sentences, such as 16. on a par. This 1s, of course, a gross simplification. Furthermore, $1 \mathrm{t}$ would be more preclse to say, instead of "varlable". "an expression containIng varlables" (to include skolemFunctions). In greater detall: ce. Hess 1985 .

\subsection{Descriptional Anaphora}

However, there $1 \mathrm{~s}$ an important type of anaphora that does not fall into this category. 15 and 16 are two examples. but we will pirst consider a pew simpler cases, namely anaphora with indefinite pronouns, 1.e. the pronoun "one(s)".

\subsubsection{Indefinite Descriptional Anaphora}

In both of the following examples, vari ants of the classical "paycheck-example". the elrst one non-seneric and the second one seneric.

17) John published a paper in 'Nature' in 1986. Feter published one in 'Science' 18) A person who published a paper in 'Nature' does not write one for the 'New Scientist.

the Indefinite pronoun "one" does not have the same denotation, or extension, as the noun phrase it $1 \mathrm{~s}$ anaphorlcally linked to. We clearly speak about two different papers (whether they be individually known, as in 17, or taken generally, as in 18). In DRT in 1 ts present form, a single discourse referent would be created for "a paper". and if we made the "one" point to It we would get the wrong loglcal interpretation (namely the one we would legitimately get if the pronoun were "1t").

We can get the correct interpretation if we treat the indefinite pronoun as a "macro". 1.e. as an abbreviation for part of the preceding sentence. Before we actually interpret the sentence, this abbreviation must be "macro-expanded" (Hirst's expression: Hirst 1981:31). 1.e replaced by a copy of the construction $1 t$ anaphorlcally points to. In the slmple exemples above we can actualiy copy the surface structure from the antecedent into the place of the pronoun. This was the explanation orlginally used in Transformational Grammar for all types of pronominal reference, but 1 soon became clear that this view was too simple. It is sufficient to consider cases where the antecedent contains indexical expressions such as "my", as in "I got my paper accepted by 'Nature'. Peter managed to get one accepted by "Science". It is not syntact1c expressions which get copled but some kind of "loglcal form", and the theory that puts this view forward is accordingly known as "1dent1ty-of-loglcal-form theory", or "ILFT" for short. In DRT, the logical form we use are DRSs, and $1 t$ w111 consequentiy be discourse referents that must be copled. During the analysis of a sentence, a "one"-pronoun must first be macro-expanded to an "empty shell" of the discourse referent it anaphorlcally polnts 
to, and the normal rules of translating DRSs into logic must then be applied to this expended form of the sentence. If we expand, for instance, the second sentence of 17 we set a representation corresponding to the discourse "John published a paper in 'Nature' in 1986. Peter published a paper in 'Science". The normal rules for translating discourse referents would now automatically create two different losical representation constants for the two discourse reperents ("paperi". "paper2"). Here the pronoun "one" does not (necessarily) refer to the same denotation as the noun phrase it anaphorlcally points to but rather to a "description" of $1 \mathrm{t}$. This type of anaphora is therefore often called "descriptions" anaphora.

There 18, however, a problem to consider that did not arise with denotational anaphora. If the sentence had been "John pub11shed a paper in 'Nature' in 1986. Peter published one, too" we would have to create a discourse referent corresponding elther to the sentence "Peter published a paper in "Nature' in 1986, too", or to "... a paper in 1986, too" or. Pinaliy. "... a paper in 'Nature', too". The problem 1s, of course, to determine what exactly alven pronoun should expand to. Th1s question w11l not be considered here. The only thing we want to do 18 to show that a very common type of anaphora. descriptional anaphora, calls for an extension of DRT which must make sure that all the parts of a sentence that can be used for expansion are represented as individualiy accessible bits of information in the DRS.

\subsubsection{Definite Descriptional Anaphora}

The two examples we started with, 15 and 16. are acceptable because they, too, are descriptional. But they are definite. as they use both the definite pronoun " $1 t$ ". Furthermore, both of them are gener1c, and so we consider this type of sentence pirst.

Again. We have to expand pronouns into newiy created discuurse referents, and again we must determine what information has to be packed into these new discourse referents. But now $1 \mathrm{t}$ is a bit clearer than with indefinite descriptional ansphora how this can be accomplished. Intultively it is clear that in sentence 16 , for Instance, the two Instances of "he" (plus one which was elliptically deleted: "... and he will carry ...") must be expanded into three different discourse referents, corresponding to "any hunter who has spotted a deer". "any hunter who has spotted and kllled a deer". and "any hunter who has spotted, killed and cut up a deer", respectively. Why do we have to use these successively more complicated expressions? Because of the definiteness of the pronoun.

The function of the definite pronoun, as opposed to the indefinite one. becomes clear if we compare example 16 with 18 . In 18 we talked about different (at least, potentlally different) papers. In 16 . however, we speak about one single hunter, although in different stages of his deerkiling activities. In other words, defin1te pronouns require uniqueness of their ultimate referent in the same way that definite noun phrases do. In the case of denotational pronouns in non-seneric sentences the uniqueness of the constants. used in HCL to encode existential quantiflcation, 1tself enforces uniqueness of the ultimate referents. But in the case of descriptional anaphora in generie sentences it is not trivial to enforce this referential uniqueness. As each seneric sentence ultimately translates into an Independent rule in the logical representation we cannot establish uniqueness of a referent named in different rules by $81 \mathrm{~m}-$ ply using the same variable name. This becomes quite obvious $1 f$ we remember that any implementation of a HCL prover. such as Prolog. must create a new internal representation for the same varlable name. when this name is used in different clauses. We can nevertheless enforce unlqueness of reference, even across generic sentences which map into separate clauses, by addine the consequences of each preceding clause to the conditions of the following one:

\author{
K1I1s(H,D) :- nunter(H), $\operatorname{deer}(D)$, \\ spots $(H, D)$. \\ cuts_up(H,D) :- nunter(H), $\operatorname{deer}(D)$, \\ spots (H,D), k111s(H,D). \\ carries_home(H,D):- hunter(H), $\operatorname{deer}(D)$, \\ spots $(H, D), k i l l s(H, D)$. \\ cuts_up $(H, D)$.
}

Thus we not only see why examples 15 and 16 are possible but also how the pronouns have to be expanded.

Definite descriptional anaphora can also occur with non-generic sentences. In

19) Here are the results of the analyses for samples 101 to 105 . The result of the analysis for sample 101 for oxygen is negative.

20) It was positive last time

21) It is positive for nitrogen

22) It is positive for sample 102

the pronoun "1t" clearly means "the result of the analysis for sample 101 for oxysen" In 20 . but "the result of the analsals for 
sample 101" In 21 and "the result of the analysis for oxygen"In 22 . If we concatenate all four sentences into one discourse we have to senerate three different discourse referents for these noun phrases. As the centence is non-generic they would sive rise to three different congtants in the loglcal representation ("result1" to "result3"). That these sertences realiy are the definite version of descriptional anaphora can also be seen from the fact that a valid paraphrase of 21 is "The one for nitrogen $1 \mathrm{~s}$ positive".

\section{AN EXTENSION OF DISCOURSE REPRESENTA- TION THEORY}

If DRT 1 s to cover descriptional anaphora (both definite and indefinite, in generic as well as in non-zenerlc sentences) we have to pack more information into discourse referents than in standerd DRT. In addition, we will have to explain how those types of ansphore thet really are impossible (such as 14) are blocked while those that are possible are not. First we want to design discourge referents which contain all the information necessary for the different types of pronominal anaohora, and then we will sketch some accessibility restrictions on this beckground.

\section{1 The Functions of Discourse Referents in Revised Discourse Representation Theory}

What kind of information must be ava11able in a discourse referent to allow the resolution of both denotationel and descriptional anaphora? Consider example 17 with indefinite descriptional anaphora. We want a loglcal representation of this discourse to look $11 \mathrm{ke}^{2}$

event (c(1), publish).

agent (John, c(1)).

Inst (c ( 2), papers).

object $(c(2), c(1))$.

location ('Nature', $c(2)$ ).

event (c(3). publish).

agent (peter, c(3)).

Inst (c(4), papers).

object $(c(4), c(3))$.

location('Science'.c(4)).

The discourse referent we introduce, for Instance, for the noun phrase "a paper" must allow the aystem to later access the constant whlch was created in the loglcal representation to stand for this particular paper ("c(2)"). In the case we have to resolve a denotational anaphora. But it

2. In the implementation we use constants such as "c(1)" rather than "paper1". and expressions like "Inst (_.pepers)" rather than "paper(_)". must also permit that, in the case of descriptional anaphora, a copy of itself is made to serve as new discourse referent, used subsequently to create a new entry in the logical representation (e.s. "Inst(c(4).papers)"). The digcourse referent should furthermore carry information about the rrammatical sender and number of the underlying word, to further Pacilitate pronoun resolution (e.s. "m+s" Por "male and singular"). A discourse referent with sufficient information could have a seneral structure like that: "dr(U,V,X,I,G+N)". "U" Is the unique 1 dentifler of this discourse referent. "V" 13 the discourse variable created for each newly introduced discourse referent, which w11 set bound to the extension as soon as the entire sentence is translated into HCL. This term, which is common to discourse referents and Horn clauses created by them, is directis accessible for denotational anaphora; it 1s, so to speak. the link erom the discourse level into the logical representation. "G+N" stand for gender and number. In "I" we have to list those elements of a sentential component which are minimeliy required for denotational anaphora. It turns out that these elements are all those of the conditions on a discourse referent that can be represented as unary predicates ( $1 . e$. malniy nouns, adjectives. and some intransitive verbs). They form. together, the intension of the phenomenon represented by the discourse referent. This would surgest the term "intensional anaphora" for what has been called "denotationel ansphora" so sar. The "X". finaliy, tells us which variable in the Intension corresponds to the discourse varlable " $V$ ", and thus the " $X$ " and "I" together correspond to "lambda X. (I)", applicable to "V". For the noun phrase "a paper" this would alve

"dr(3,V,X, [1nst (X.papers)], n+s)".

The DRS for the entire example 17 then looks like that:

[ [dr (1, john, $S,[$ inst $(S$, humans) ], m+s), dr (2, nature, $T,[$ inst ( $T$, journals) $], n+s)$, dr $(3, C(1), U,[$ inst (U, papers) $], n+s)$, dr $(4, c(2), V$, Cevent ( $V$, publ ish), agent $(S, V)$, object $(U, V)$, place $(T, V), t i m e(1986, V)], n+s)]$ $\operatorname{dr}(5$, peter, $w,[$ inst ( $w$, humans) $], m+s)$, dr $(6, s c i e n c e, X,[$ inst $(X, j o u r n a l s)], n+s)$, dr $(7, c(3), Y,[$ inst ( $Y$, papers) $], n+s)$, dr $(B, c(4), Z$, Levent $(Z$, publ ish), agent $(S, Z)$, object $(Y, Z)$ place $(X, Z), t i \operatorname{me}(1986, Z)], n+5)]$ : $1,2,3,4,5,6,7,8]$

The last line glves the overall loglcal structure of the entire DRS and states here that all the conditions in the named discourse referents have to be entered 
confunctively into the loglcal representation, as shown above. This overall loglcal structure is all that 18 left of the "conditions"-part of traditional discourse referents, and most information orisinaliy encoded in this "conditions"-part has been moved into the discourse referents. This is closer to Heim's notation (for "Plle cards") than to Kamp's.

A generic sentence w1Il be translated into HCL rules. With variables. "If a hunter spots a deer he will k11l 1t" will become

\author{
event $(C(1,(H, D, W)), k i 11):-$ \\ inst ( $H$, hunters), \\ inst ( $D$, deer), \\ event ( $w$, spot), \\ agent $(H, W)$, object $(D, W)$. \\ agent $(H, C(1,(H, D, W)))=-$ \\ inst ( $H$, hunters), \\ inst ( $D$, deer). \\ event ( $w$, spot), agent $(H, W)$, \\ object $(D, W)$. \\ object $(D, C(1,(H, D, W)))$ :- \\ inst ( $H$, hunters), \\ inst ( $D$, deer), \\ event ( $W$, spot), agent $(H, W)$, \\ object $(D, W)$.
}

where the expression event " $c(1,(H, D, W))$ " is a Skolem function (more commonly written as "sk1(H,D,W)"). In order to get this loglcal representation we will have to generate discourse referents such as "dr(1,v(2), X, [1nst (x, hunters)],-+s)" for "a nunter". where the discourse varlable 18 bound to " $v(2) "$ ". the discourse level representation of an object level variable ("H". "D", etc.). The DRS for the entire sentence will be

$[[\operatorname{dr}(1, v(1), R,[$ inst (R, hunters) $],++5)$, $\operatorname{dr}(2, v(2), s,[1 \mathrm{nst}(\mathrm{s}$, deer $)], n+8)$. $\operatorname{dr}(3, v(3), T$, [event ( $T$, spot), agent (R,T), object $(S, T)], n+8)$, $\operatorname{dr}(4, v(4), U,[$ event $(U, k 111)$. object $(v(2), v(4))], n+8)\}$ $: 1,2,3 \rightarrow->4$ ]

Again the last line outlines the logical structure which 18 used to create the entries in the losical representation.

\subsection{Accessibility Restrictions in Revised Discourse Representation Theory}

We noted above that classical DRT deflnes accessibility restrictions which rule out some perfectly lexitimate examples. such as 15. We think that the accessibility restrictions that really hold, are the result of interactions between the senerloness of the sentences involved, and the genericness of a sentence 18 reflected (among other things) in the type of discourse referents 1 t renerates. Example 14 starts out with a senerte statement and suddenly switches over to a non-generic statement whereas the acceptable examples 15 and 16 consist of two senerlc sentences. It seems to be this switch of genericness which makes the pronominal reference impossible in example 14 , and not the fact that we point into a quantiPled sentence. 'But it is not necessary that the sentences concerned belong to the same genericness category. The first of the following examples is unacceptable but the second and third examples are acceptable, despite mixed gencricness:

23) * Whenever a farmer spots a donkey he abuses it. He is beating and kicking it right now.

24) Whenever Pedro spots a donkey he abuses it. He is beating and kicking one right now.

25) There is a farmer beating and kicking a donkey. I ve seen him before. Whenever he spots it he abuses it.

Th1s asymetry finds an explanation in the pact that non-generic sentences. such as the second sentence of example 23, (almost always) speak about individuals. A pronoun in such a sentence is therefore (in almost all cases) a denotational pronoun, trying to Pind an extensional value in an antecedent which could be used as 1 ts own denotation. Hence we will have to make sure that a denotational pronoun accepts only representstions of lndividuels (of the form "c(X)") in the preceding sentence(s), and that a pallure to find them must result in the entire discourse becoming unacceptable. Thus the "he" and "1t" In the second sentence of example 23 will try to find representations of ind1viduals in the pirst sentence, but there are only representations of "stereotypes". 1.e. meta-level names for object level varlables (op the form "v(X)"). This makes denotational anaphora imposible in this case.

3. Baslcally the same 1dea was developed by Bartsch 1979. though not in the eramework of DRT. She says that pronouns such as those in 15 and 16 refer to stereotypes of objects rather than to the objects themselves. However, we think she overstretches this ldea by claimine that ordinary donkeysentences must be explained by means of stereotypes, also. There are. after all, perfectly non-generic donkey-sentences, such as "Every farmer who bought a donkey slaughtered 
The same problem does not arise in example 24. Here we have an explicitly descriptional pronoun ("one"), and 1 t will not care about the type of value that 1 ts antecedent has (1.0. Whether it is "c(X)" or "v(x)"), as 1t will only use the antecedent's intension anyway.

Example 25. Pinally. 1s acceptable because senerle sentences can talk about either Individuals or "stereotypes". Although the third sentence ("Whenever he spots it he obuses 1t.") 1s ceneric, the pronouns in it will first try to find denotations in their antecedents. In this case, they will succeed: The pirst sentence of 25 is nongenerlc and has, of course. created representations of individuals (1.e. "c(X)"). If there had been no suitable extensional antecedents, the pronouns would have started looking for intensional ones. This was the case in examples 15 and 16. In examples 19 to 22, Inally, there were actually extenslonal antecedent values, but pragmatic considerations (1.e. world knowledge) forces the hearer in these cases to drop the (formaliy posilble) denotational anaphora in pavour of (depinite) descriptional anaphora. Just Pinding Intensional antecedents of descriptional pronouns 1s, however. not enough: You have then to decide how much of the intension (often scattered over several discourse referents) has to be copied in the place of the pronoun. But this is an other question altogether. often involving inferences over world knowledge. plausible reasoning etc., which cannot be dealt with here.

\section{REFERENCES}

Bartsch 1979: Bartsch, R.. The Syntax and Semantics of Subordinate Clause Constructions and Pronominal Coreference, In: Selections from the Third Groningen Round Table: Syntax and Semant1cs; Heny, F.. and Schnelle, H.S., eds. Pp.23-59, Academic Press, New York, 1979

Eijck 1983: van E1jck, J.. Discourse representation theory and plurality, in: Studies in Modeltheoretic Semantics, ter Meulen, A.G.B.. ed.. PP. 85-106, For1s. Dordrecht/Cinnamingon, 1983
Evans 1980: Evans, G.. Pronouns, in: Linguistic Inquiry, 11, (2), Pp. 337-362. 1980

Guenthner 1986: Guenthner, F., Lehmenn, H., Schonfeld, W.: A theory for the representation of knowledge, in: IBM $J$ Res Develop, vol. 30, $\mathrm{nr}, 1 . \mathrm{pp} .39-56,1986$

Hausser 1979: Hausser, R.R., How do Pronouns Denote?. Selections from the Third Groningen Round Table; Syntax and Semant1cs. pp. 93-139. Heny. F., and Schnelle, H.S. eds.. Academlc Press, New York, 1979

Heim 1983: Heim, I. File Change Semantics and the Familiarity Theory of Definiteness, In: Meaning. Use, and Interpretation of Language; Baeuerle, R., schwerze, Ch.. von Stechow, A., eds.: Pp. 164-189, de Gruyter, Berlin/New York. 1983

Hess 1985: Hes8, M., How Does Natural Language Quantify ? In: Proceedings of the Second Conference of the European Chapter of the Association for Computational Linguist1c8; PP. 8-15. Walker. D.. ed. Geneva, 27-29 March 1985

Hirst 1981: H1rst. G.. Anaphora in Natural Language Understanding. Lecture Notes in Computer Science 119. Springer-Verlag. Berlin/Heidelberg/New York, 1981

Johnson 1985: Johnson, M. . and Kle1n, E., A Declarative Formulation of DRS Theory. Lecture Notes, ASL Talk, Stanford CA, 1985

Karttunen 1976: Karttunen, L.. D1scourse Referents, Notes from the Linguistic Underground, PP. 363-385. McCawley, J.D. ed.. Academic Press, New York/San Franc1sco/London, 1976

Pinkal 1986: Plnkal, M. Depinite Noun Phrases and the Semantics of Discourse, 1n: Proceedings of the 11th International Conference on Computational Linguistics, pp. 368-373. Bonn, 1986

Webber 1983: Webber, B. L., So What Can We Talk About Now?, In: Computational Models op Discourse, Brady, $M$. and Berwick. R.C. eds.. ch. 6. PP. 331-371, The MIT Press Serles in Artiflcial Intelligence, MIT Press, Cambridge MA, London, 1983 1t". and stereotypes are entirely out of place here. 